\title{
Disorders of Adhesions or Adhesion-Related Disorder: Monolithic Entities or Part of Something Bigger-CAPPS?
}

\author{
David M. Wiseman, Ph.D., M.R.Pharm.S. ${ }^{1}$
}

ABSTRACT

The purpose of this article is to review progress in the field of abdominopelvic adhesions and the validity of its two underlying assumptions: (1) The formation of adhesions results in infertility, bowel obstruction, or other complications. Reducing or avoiding adhesions will curb these sequelae. (2) "Adhesions" is a monolithic entity to be tackled without regard to any other condition.

Evidence is discussed to validate the first assumption. We reviewed progress in the field by examining hospital data. We found a growing trend in the number and cost of discharges for just two adhesion-related diagnoses, and the low usage of adhesion barriers appears in at most 5\% of appropriate procedures. Data from an Internet-based survey suggested that the problem may be partly due to ignorance among patients and physicians about adhesions and their prevention.

Two other surveys of patients visiting the adhesions.org Web site defined more fully adhesion-related disorder (ARD). The first survey $(N=466)$ described a patient with chronic pain, gastrointestinal disturbances, an average of nine bowel obstructions, and an inability to work or maintain family or social relationships. The second survey (687 U.S. women) found a high (co-) prevalence of abdominal or pelvic adhesions (85\%), chronic abdominal or pelvic pain (69\%), irritable bowel syndrome (55\%), recurrent bowel obstruction (44\%), endometriosis (40\%), and interstitial cystitis (29\%).

This pattern suggests that although "adhesions" may start out as a monolithic entity, an adhesions patient may develop related conditions (ARD) until they merge into an independent entity where they are practically indistinguishable from patients with multiple symptoms originating from other abdominopelvic conditions such as pelvic or bladder pain. Rather than use terms that constrain the required multidisciplinary, biopsychosocial approach to these patients by the paradigms of the specialty related to the patient's initial symptom set, the term complex abdominopelvic and pain syndrome (CAPPS) is proposed.

It is essential to understand not only the pathogenesis of the "initiating" conditions but also how they progress to CAPPS. In our ARD sample, not only was the frequency of women with hysterectomies (56\%) higher than expected (21 to 33\%), but also the rates of the "initiating" conditions was 40 to $400 \%$ higher in patients with hysterectomies than in those without. This may represent increased surgical trauma or the loss of protection against oxidative stress. Related was the higher frequency of ARD patients reporting hemochromatosis $(\mathrm{HC} ; 5 \%)$ than expected $(\sim 0.5 \%)$ and the higher rates $(20$ to

${ }^{1}$ Synechion, Inc., and International Adhesions Society, Dallas, Texas. Address for correspondence and reprint requests: David $\mathrm{M}$. Wiseman, Ph.D., PMB 238, International Adhesions Society, 6757 Arapaho, Suite 711-238, Dallas, TX 75248 (e-mail: david.wiseman @adhesions.org).
Postsurgical Adhesions; Guest Editor, Michael P. Diamond, M.D. Semin Reprod Med 2008;26:356-368. Copyright (C) 2008 by Thieme Medical Publishers, Inc., 333 Seventh Avenue, New York, NY 10001, USA. Tel: +1(212) 584-4662.

DOI 10.1055/s-0028-1082394. ISSN 1526-8004. 
700\%) of initiating conditions in patients with $\mathrm{HC}$ than in those without $\mathrm{HC}$. Together with findings related to the toxicity of Intergel, these findings raise the possibility that heterozygotes for genes regulating oxidative stress are at greater risk of developing surgical complications as well as more severe and progressive conditions such as CAPPS.

KEYWORDS: Adhesions, adhesion-related disorder, complex abdominopelvic and pain syndrome, chronic pelvic pain, hysterectomy, iron overload, hemochromatosis

The history of adhesion prevention has been analyzed in terms of six epochs ${ }^{1}$ divided principally according to the level of sophistication of the approaches used. The period referred to as "The Industrial Revolution" starting around 1989 was marked by the introduction of Interceed (1989; Ethicon, Inc, Somerville, NJ), ${ }^{2}$ Seprafilm (1996; Genzyme Corp; Cambridge, MA), ${ }^{3,4}$ Preclude (ca. 1990; WL Gore \& Associates, Flagstaff, AZ) $)^{5}$ and Adept (2007; Baxter Healthcare Corporation, Deerfield, IL). Hyaluronic acid, Flogel (poloxamer; Alliance Pharmaceutical Corp., San Diego, CA), tolmetin, Focalgel (Focal, Inc., Lexington, MA), and tissue-type plasminogen activator were all evaluated for adhesion prevention, but did not reach the point of regulatory submission. Sepracoat (1997; Genzyme Corp, Cambridge, MA) ${ }^{6}$ was denied approval, and Intergel (2002; Ethicon, Inc., Somerville, NJ) ${ }^{7}$ was approved but withdrawn for safety reasons. ${ }^{8}$ Adcon-L (1998; Gliatech, Inc., Cleveland, $\mathrm{OH}$ ) was approved for spinal surgery but later withdrawn. Seprafilm II was briefly available in Europe but discontinued, and SprayGel (Covidien, Mansfield, MA), and Hylagel (Fidia Advanced Biopolymers, s.r.l. Abano Terme, Italy) remain available only outside the United States.

This "Industrial Revolution" has fueled an explosion in our grasp of abdominopelvic adhesions and its etiology, ${ }^{9-11}$ epidemiology, ${ }^{12,13}$ cost,${ }^{14-16}$ prevention in human ${ }^{17}$ and animal ${ }^{18}$ models, as well as its clinical manifestations of pain, infertility, and bowel obstruction. ${ }^{10,19-21}$ Two assumptions underlying the contemporary study of adhesions and their prevention are the following:

1. The formation of adhesions results in infertility, bowel obstruction, or other complications. Reducing or avoiding adhesions will curb these sequelae.

2. "Adhesions" is a monolithic entity to be tackled without regard to any other condition.

The purpose of this article is to review our progress in the field and its underlying assumptions.

\section{DOES REMOVAL OR AVOIDANCE OF ADHESIONS IMPROVE PATIENT OUTCOMES?}

It has long been argued that the collection of outcomebased data for regulatory purposes would be impractical due to the multifactorial nature of pain and infertility or the prolonged follow-up required in large numbers of patients to evaluate bowel obstruction. ${ }^{22}$ Nonetheless, studies have emerged that permit us to test our hypotheses that the removal (i.e., adhesiolysis) or avoidance of adhesions (i.e., use of adhesion barriers) will result in clinical benefits.

\section{Adhesion Reduction and Surgical Complications}

That the reduction in adhesion formation would result in the overall reduction of surgical complications is obvious from the several epidemiologic studies finding that approximately one third of patients undergoing abdominal or pelvic surgery were admitted nearly twice in the next 10 years for a problem related to adhesions or that could be complicated by adhesions. ${ }^{13,23}$ The same argument is justified from the numerous studies showing the reduction in incidence, extent, or severity of adhesions using a variety of adhesion barriers. More direct evidence comes from a small retrospective study involving 52 patients undergoing a second cesarean section, which found that delivery times and operative times were reduced in patients having Seprafilm placed at a first cesarean section compared with those in patients where Seprafilm was not used. Blood loss was also reduced but did not reach significance. ${ }^{24}$ Relaparotomy time was also reduced in children treated with Seprafilm $(N=67)$ undergoing abdominal surgery compared with that of control patients. ${ }^{25} \mathrm{~A}$ prospective randomized study failed in 191 patients to demonstrate any significant differences in the time to close a loop ileostomy if Seprafilm had been used at the time of ileostomy creation. This failure was attributed to the variability in techniques used by the large number of surgeons (29) participating in the study. ${ }^{26}$

\section{Adhesion Reduction and Infertility}

The American Fertility Society (AFS) classification of adnexal adhesions ${ }^{27}$ inherently acknowledges an inverse relationship between adhesions and fertility ${ }^{28}$ and has been confirmed in two ways. First, pregnancy rates have correlated with AFS scores (before adhesiolysis) in prospective settings by both laparotomy ${ }^{29}$ and laparoscopy. ${ }^{30}$ Second, the pregnancy rates among infertile 
women treated by salpingo-ovariolysis was higher (45\%) than that among matched untreated patients (16\%). ${ }^{31}$ Although the hypothesis that fertility can be improved using an adhesion barrier remains untested prospectively, $78 \%$ (18 of 23) of patients undergoing reconstructive pelvic surgery treated with Interceed barrier became pregnant compared with only $47 \%$ (7 of 15) of control patients. $^{32}$

\section{Adhesion Reduction and Bowel Obstruction}

The relationship between bowel obstruction and adhesions is well-known ${ }^{19,21,33}$ and the management of bowel obstruction well described. ${ }^{19,34,35}$ Recently, Seprafilm was shown to reduce the rate of adhesive small bowel obstruction (SBO) requiring operation from $3.4 \%$ to $1.8 \%$ in 1701 patients undergoing small bowel resection with a follow-up of 2 to 5 years. ${ }^{36}$ In two smaller retrospective series, Seprafilm reduced early SBO after surgery from $14 \%$ (26 of 183) to $6.5 \%$ (12 of $184)$ in patients undergoing gastrointestinal surgery ${ }^{37}$ and from $20 \%$ (6 of 30 ) to $0 \%$ (0 of 21 ) in patients undergoing surgery for transabdominal aortic aneurysm. ${ }^{38}$ A meta-analysis failed to detect a benefit of Seprafilm in terms of postoperative intestinal obstruction. $^{39}$

\section{Adhesion Reduction and Pain}

The relationship between adhesions and chronic abdominal or pelvic pain is more controversial. ${ }^{21,40,41}$ Adhesions may cause pelvic pain by tethering tissues, causing nerve traction, or by entrapping nerves. Indeed, nerve endings have been found within adhesions. ${ }^{42}$

Not all adhesions cause pain, and not all pain is caused by adhesions. Part of the problem appears to be in the complex way pain is referred within the abdominal cavity as evidenced from studies involving conscious pain mapping. Furthermore, the conventional view that dense vascular adhesions are "worse" than filmy adhesions is challenged by observations that higher pain scores are associated more with filmy adhesions between movable structures rather than fixed or dense adhesions. ${ }^{43}$ Twenty-five percent to $57 \%$ of patients with chronic pelvic pain (CPP) are estimated to have adhesions, with or without endometriosis. ${ }^{44}$ In $75 \%$ of patients with a physical source of pain, emotional factors contribute greatly to the perception of pain and the ability to cope with it.

Despite the uncertain relationship between adhesions and pain, adhesiolysis does provide some relief. In a German study ${ }^{45}$ involving laparoscopic adhesiolysis in female and male patients with chronic abdominal pain, there was a complete remission of pain in $45 \%$ of the patients, with $35 \%$ of patients reporting a substantial improvement up to 30 months. Other improve- ments were reported in the United States ${ }^{46,47}$ and The Netherlands. ${ }^{48}$ That these effects may be rooted in a "therapeutic" effect of laparoscopy itself alone is not clear as patients without obvious pathology undergoing diagnostic laparoscopy also reported a reduction or cessation of pain. ${ }^{49}$

To test this further, 100 patients undergoing diagnostic laparoscopy for chronic abdominal pain were randomized to adhesiolysis or no treatment. ${ }^{50}$ Patients and assessors were blinded. Forty-two percent of patients undergoing diagnostic laparoscopy reported improvement or remission at 12 months compared with $57 \%$ with adhesiolysis. The authors' conclusion that although laparoscopic adhesiolysis relieved pain, it was no better than diagnostic laparoscopy, may reflect a type II error. Further, the apparent benefit of laparoscopy alone suggests that the source of pain in these patients may originate less from pathologic (i.e., adhesions) foci in the abdomen and more from higher levels in the nervous system. Whether this "placebo" effect is related to that reported in arthroscopy ${ }^{51}$ is unclear, although a more recent prospective and randomized study in endometriosis patients undergoing laparoscopy also suggests a positive effect of "sham" surgery. ${ }^{52}$ Lastly, the likely reformation of adhesions in at least $75 \%$ of surgical sites $^{53}$ may have abrogated any positive effect of adhesiolysis. In fact, the difference in pain reduction between the adhesiolysis and control groups would be consistent with the expected degree of improvement from adhesiolysis. Perhaps with a reduction of 25 to $30 \%$ in the incidence of adhesions (by site) that could be achieved with adhesion barriers, an effect of adhesiolysis on pain may have been more apparent. Indeed, in an uncontrolled series of 19 patients undergoing laparoscopic adhesiolysis with placement of Seprafilm for chronic intractable abdominal pain, 14 (74\%) patients had discontinued pain medications at follow-up of up to 32 months. $^{54}$

\section{REMOVAL OR AVOIDANCE OF ADHESIONS MAY IMPROVE PATIENT OUTCOMES - NOW WHAT?}

The emerging evidence does support the notion that curbing adhesions improves outcomes for patients. But it is clear that there is a long way to go to eliminate the problems of adhesions

Our own analysis of discharge data from the Nationwide Inpatient Sample for the period 20012005 reveals a growing trend in the numbers of discharges for just two ICD-9-CM diagnosis codes (Table 1). A somewhat steady 2100 to 2400 patients a year have died with a principal diagnosis of Intestinal Adhesions with Obstruction (560.81), which produced in 200573,881 discharges and some $\$ 3.45$ billion of charges. But this is just the tip of the iceberg. When 
Table 1 Hospital Discharge Data for Two Adhesion-Related Codes and Use of Barriers

\begin{tabular}{|c|c|c|c|c|c|}
\hline & \multicolumn{5}{|c|}{ Year } \\
\hline & 2001 & 2002 & 2003 & 2004 & 2005 \\
\hline \multicolumn{6}{|l|}{ ICD-9-CM Diagnosis Code 568.0 Peritoneal Adhesions } \\
\hline \multicolumn{6}{|l|}{ All Diagnoses-Discharges } \\
\hline All discharges & 156,621 & 168,154 & 172,935 & 180,806 & 186,387 \\
\hline Female percent of total (\%) & 74 & 73 & 72 & 73 & 72 \\
\hline \multicolumn{6}{|c|}{ ICD-9-CM Diagnosis Code 560.81, Intestinal Adhesions with Obstruction } \\
\hline \multicolumn{6}{|l|}{ All Diagnoses-Discharges } \\
\hline All discharges & 89,048 & 91,664 & 88,965 & 94,708 & 99,075 \\
\hline Female percent of total (\%) & 63 & 62 & 62 & 62 & 62 \\
\hline \multicolumn{6}{|l|}{ Principal Diagnosis Only-Deaths } \\
\hline All & 2219 & 2366 & 2311 & 2140 & 2118 \\
\hline Female & 1396 & 1404 & 1418 & 1264 & 1285 \\
\hline Female deaths as percent of female discharges (\%) & 3.25 & 3.19 & 3.36 & 2.81 & 2.78 \\
\hline 99.77 Application of Adhesion Barrier & & - & - & 23,813 & 30,105 \\
\hline
\end{tabular}

Source: Healthcare Cost and Utilization Project, Agency for Healthcare Research and Quality.

other inpatient diagnoses of peritoneal and pelvic adhesions are added, the financial cost of adhesions easily exceeds $\$ 5$ billion, and that is before outpatient costs and loss of work are considered.

The use of adhesion barriers as evidenced from code 99.77 is also very low. This is almost certainly an underestimate. Based on estimated sales of adhesion barriers of $\$ 100$ million, an average price per unit of $\$ 200$, and an average usage of 1 unit per procedure, adhesion barriers are only used, conservatively, in 500,000 procedures annually. To estimate their potential usage, assuming that obstruction due to adhesions represents $1 \%$ of general surgical admissions in 1 year, ${ }^{55}$ then the figure of 99,075 discharges for intestinal adhesions with obstruction represents some 9.9 million procedures where barriers might be used. The percentage of procedures in which adhesion barriers are used is at best a little over $5 \%$.

Solving the problem of adhesions may be broken down into four main tasks:

1. Develop more effective antiadhesion agents for a variety of indications both by laparotomy and laparoscopy.

2. Expand basic research beyond that currently conducted by a handful of laboratories.

3. Increase physician and patient awareness about adhesions and their prevention to improve the use of adhesion barriers and other techniques, leading to more chances for improved outcomes.

4. Challenge the paradigms on which are based contemporary efforts in adhesion prevention. Is it time for a different look?

The development of more advanced antiadhesion agents has been discussed elsewhere, ${ }^{1,56}$ and other contributions in this issue of Seminars in Reproductive
Medicine provide a glimpse of the excellent basic research being conducted in the field. The last two items will be discussed further here.

\section{IMPROVING PHYSICIAN AND PATIENT AWARENESS ABOUT ADHESIONS}

The ramifications of physician and patient ignorance about adhesions has long been the subject of debate in the boardrooms of medical product companies and the barrooms of conferences on adhesions. Corporate advertising as well as sponsorship of several excellent studies such as those analyzing data from the Scottish National Health Service ${ }^{12,13}$ has greatly increased awareness of adhesions. Revolutionizing patients' access and use of medical information, the Internet has spawned the proliferation of Web sites promoting research and awareness and providing information and support to families and patients affected with all manner of conditions, particularly those heretofore relegated to obscurity in medical textbooks. Accordingly, in 1996 we formed The International Adhesions Society, and its adhesions.org Web site now receives more than 100,000 visitors monthly. Ignorance about adhesions among patients and physicians is frequently reported to us, arguably delaying diagnosis and treatment and inflicting additional suffering on patients shunned by their physicians, employers, and families as malingerers.

To characterize the causes of this ignorance, patients who had abdominal or pelvic surgeries were surveyed via the Internet ${ }^{57}$ about information given them prior to surgery regarding adhesions and adhesion barriers. Five hundred seventy (43 male, 527 female) patients responded concerning 952 procedures. Patients reported being informed about adhesions prior to $27 \%$ of the procedures they underwent. In only 122 (12.8\%) of these were adhesions mentioned as part of the informed 
consent, and in another 132 (13.9\%) adhesions were discussed. Information was imparted about adhesions in $55 \%$ of adhesiolysis procedures and in $9.3 \%$ of nonadhesiolysis procedures. Patients reported being provided with information about adhesion barriers in $46 \%$ and $6 \%$ of adhesiolysis and non-adhesiolysis procedures, respectively. Where adhesions were mentioned, barriers were mentioned in $46 \%$ of adhesiolysis procedures and in $22 \%$ of non-adhesiolysis procedures. Despite several obvious caveats involved in interpreting a study of this kind, it suggests the preoperative consultation and consent procedures may offer the ideal opportunity to educate patients about adhesions. Beyond medicolegal reasons for discussing adhesions, ${ }^{58}$ patients do want to know about their treatment and its risks. ${ }^{59}$ Even if they do not fully understand the information provided, ${ }^{60}$ training (or even requiring) physicians to discuss adhesions with patients forces them to consider a strategy for their reduction.

\section{CHALLENGING THE PARADIGMS OF ADHESIONS RESEARCH: IS IT TIME FOR A DIFFERENT LOOK?}

\section{Viewing the Problem as Adhesion-Related Disorder}

Despite the increasing volume of work conducted, adhesions research has been practically compartmentalized, as if "adhesions" was an independent entity. Accordingly, the approach to "adhesions" patients was much like any monolithic disease but was clearly not meeting the needs of thousands of "adhesions" patients seeking referrals or other information. Why? Because we lacked effective antiadhesion agents? Because we did not fully understand the pathogenesis of adhesions? Because of ignorance about adhesions and their prevention? Perhaps it was because we wrongly assumed that "adhesions" is an independent and monolithic problem.

To determine the best approach to the "adhesions" patient, we first tried to describe more fully the condition of the "adhesions" patient. From hundreds of e-mails and telephone interviews, a typical picture of an "adhesions" patient emerged of a 30- to 50-year-old woman with several abdominal surgeries, including a hysterectomy and several bowel obstructions. She had chronic pain, could not eat properly, and had already seen several physicians who had told her that there was little to be done. The patient was desperate and frustrated and her family, social, and employment relationships were deteriorating.

An Internet-based survey was conducted to quantify what we had learned from our anecdotal library. ${ }^{61}$ Four hundred sixty-six patients (51 male, 415 female) reported having a diagnosis of adhesions for $7.0 \pm$ 0.3 years. Sixty-eight percent of patients reported an average of $9.5 \pm 0.7$ full or partial obstructions. Most of these respondents seem to represent a severe form of "adhesions" perhaps a notch or two below the 2100 or so patients dying annually with a primary diagnosis of intestinal adhesions with obstruction (Table 1). These data are consistent with descriptions of a living hell in which each of the sometimes $>25$ adhesiolysis procedures offers only a temporary respite of less than a year from obstruction and debilitating pain. Indeed, $81 \%$ of respondents reported chronic pain of whom $68 \%$ took medication. In $68 \%$ of those patients, the medication worsened their bowel symptoms. Seventy-one percent of patients reported gastrointestinal disturbances, including $52 \%$ with chronic or severe constipation, $30 \%$ with chronic or severe diarrhea, and $24 \%$ with malabsorption problems. The totality of these patients' suffering could not adequately be described by the monolithic term "adhesions" and so was coined the term adhesion-related disorder (ARD).

Our anecdotal impression that ARD compromises a patient's ability to work was verified by $42 \%$ of respondents, $47 \%$ of whom could not obtain disability benefits. As a result of their condition, patients reported that either their relationships had suffered (57\%) or their friends and family were not supportive (44\%), or both (27\%), with only $26 \%$ reporting intact relationships and supportive friends and family.

Commonly reported feelings of isolation and "craziness" are illustrated in the following excerpts from e-mails we received (without correction of spelling or grammar):

- have had 15 srgys. Each time the doctors go in they say I had so much ashesions. I had a hsty 4 years ago because of endo. Now the pain is back in full force. At first I thought I was crazy... I do not no how long I can deal with this pain. Its so bad. Is there anyone who has gone though this before. I could really use some encouragement right now. I thought the pain was gone after the hsty. I guess I was wrong (9/9/2002).

- I have been suffering with endometriosis, adhesions, and IC [interstitial cystitis] for the past 13 years. I have had 24 surgeries and still live in constant pain from adhesions.... Without pain meds I cannot take care of my children or my husband. I cannot work anymore.... The adhesion site has been a savior to me at a time in my life when I thought I was all alone. Now I know I am not alone and there are other alternatives to just living in pain the rest of my life (5/10/2004).

- I thought I was the only one. I have had 12 surgeries to control the adhesions.... I thought I was going to beat this one, but now the symptoms have returned and all my hope has gone.... Thanks for posting this Website where I can know i'm not the only one.(4/17/2006).

In the extreme, some patients reported considering or attempting suicide: 
- i really don't know what to do anymore... ii am to scared to ask for help but i really want it... I am so ready to just commit suicide but i never succeed (10/9/ 2003).

- I.... feel suicidal trying to cope with ARD (3/6/ 2006).

- I lost another ARD patient this past weekend to suicide. Her family and friends were no support for her. $\mathrm{He}[\mathrm{r}$ husband] was told her only problem was addiction to pain meds. That was the last straw,... (from an ARD volunteer 10/2/2006).

- I had a full hysterectomy... I am in constant pelvic/ abdominal pain.... had.... additional surgeries for adhesions.... I am still in constant pain 24-7 . ... I am so depressed with thoughts of suicide, however, my deep faith will always prevent me from doing this (12/ 24/2004).

Based on anecdotal reports, patients were also asked about their use of physical therapy. In the $26 \%$ of patients using it, 29\% benefited. Such therapy has been widely reported to benefit patients with a diagnosis of chronic pelvic pain. ${ }^{62}$ Forty percent of patients reported that their physician was able to help their condition somewhat, with another 51\% reporting that their physicians acknowledged their problem but were unable to help. Contrary to earlier impressions, only $9 \%$ of patients reported that their physicians denied their problem and were unwilling to help.

\section{Viewing ARD in the Context of Complex Abdominopelvic and Pain Syndrome (CAPPS)}

The term $A R D$ still leaves the same frustrated and desperate patient traversing continents and oceans in the hope of finding that one physician with "the secret" to their suffering. Continuing to puzzle us are observations that severe $A R D$ patients are temporarily relieved of pain after adhesiolysis, and when pain recurs they are adhesion-free (and free of other pathology) at laparoscopy. Equally puzzling is the improvement in pain after diagnostic laparoscopy alone in patients with adhesions. ${ }^{50}$ If by using the term $A R D$ we have succeeded in acknowledging the existence of ARD patients' numerous symptoms, we continue to fail practically by assuming that they are all related by the common denominator of adhesions. As will be explained, a more successful approach may be derived by examining the problem of ARD in the context of a much larger problem of what we have termed complex abdominopelvic and pain syndrome (CAPPS) defined operationally as:

a syndrome of nonmalignant origin consisting of a complex of symptoms of the abdomen or pelvis that includes pain, bowel, or bladder dysfunction of at least 6 months duration.
Both sides of the debate about whether adhesions cause pain have failed to consider neurologic changes that occur in chronic pain. Although acute or subchronic pain may be due to surgically correctible pathology (i.e., adhesions, endometriosis, etc.), once pain has become chronic (e.g., 6 months), changes in the spinal cord and dorsal root ganglia ${ }^{63-65}$ result in the transmission of unsolicited, inappropriate, and uncontrolled impulses to the pain centers of the brain. Pain itself becomes the disease state rather than a local cause. Although pain can be temporarily arrested by the removal of triggers such as endometriosis and adhesions, pain may inevitably return because the neural changes themselves have not been addressed, akin to the phenomenon of phantom limb pain. ${ }^{66}$ Indeed, phantom bladder pain has been reported in patients after cystectomy. ${ }^{67,68}$

But the story continues. The complex neuroanatomy of sacral, lumbar, hypogastric, and pelvic plexi ${ }^{69,70}$ affords many opportunities for cross-talk between the nerves of abdominal and pelvic tissues. ${ }^{71}$ Impulses once appropriate from one organ may trigger impulses in a nearby pathway, deceiving the brain into believing that they have originated elsewhere. Further, pathology in one organ (e.g., uterus, bladder, bowel) may induce pathology ${ }^{72}$ or hypersensitivity ${ }^{73-75}$ in another. Thus, a patient in whom only one organ was affected initially may develop a problem in another.

Many studies attest to the coprevalence between various abdominal and pelvic disorders ${ }^{76,77}$ including adhesions. ${ }^{78}$ A similar pattern of organ involvement appears to exist from our preliminary analysis of 687 female ARD patients from the United States responding to our Internet-based survey (Table 2). Focusing on adhesions and calculating the cumulative coprevalence of the five most frequent diagnoses or

Table 2 Conditions and Diagnoses Reported by U.S. Women Visiting an Adhesions-Oriented Web Site

\begin{tabular}{lrl}
\hline Condition or Diagnosis & N & $\begin{array}{l}\text { Percent of } \\
\text { Total (\%) }\end{array}$ \\
\hline All U.S. women & 687 & 100 \\
Adhesions: abdominal & 532 & 77 \\
Adhesions: pelvic & 433 & 63 \\
Adhesions: abdominal or pelvic & 582 & 85 \\
Chronic abdominal (not pelvic) pain & 383 & 56 \\
Chronic pelvic (not abdominal) pain & 383 & 56 \\
Chronic pain: abdominal or pelvic & 471 & 69 \\
Irritable bowel syndrome & 376 & 55 \\
Recurrent bowel obstruction & 299 & 44 \\
Endometriosis & 270 & 40 \\
Interstitial cystitis & 197 & 29 \\
Fibroids & 183 & 27 \\
Pelvic Inflammatory Disease (PID) & 98 & 14 \\
Hemochromatosis or iron overload disorder & 47 & 7 \\
Previous hysterectomy & 387 & 56 \\
\hline
\end{tabular}




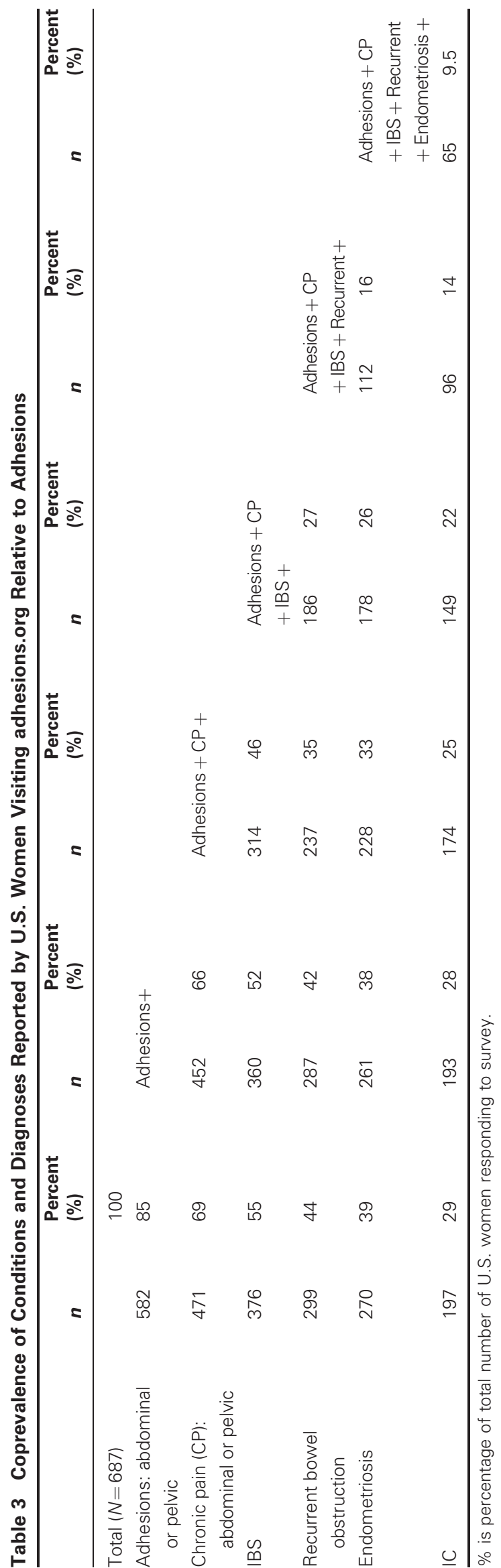

conditions, in descending order of prevalence (Table 3), the data reveal a high degree of overlap between abdominal or pelvic adhesions, chronic abdominal or pelvic pain, irritable bowel syndrome (IBS), recurrent bowel obstruction, endometriosis, and interstitial cystitis.

These data suggest that the severe "ARD" patient suffers from a similar multifaceted, multiorgan phenomenon as the "chronic pelvic" or the "chronic bladder" pain patient. Even if patients from each of these groups started with just one condition, as each condition progressed, it began to overlap and coalesced with the other into the entity we have termed CAPPS. Although $\sim 15$ million women alone suffer from chronic pelvic pain, we have conservatively estimated that there are 150,000 to 250,000 women with the most severe form of the disease (as CAPPS), a high proportion of who will most likely have adhesions.

Without the perspective of CAPPS, a patient is at the mercy of compartmentalized medical practice. Although the severe CPP/IC/ARD patient is likely to display several seemingly unrelated symptoms, the most dominant one will determine the specialty to which the patient is initially referred. Unexplained dysmenorrhea or dyspareunia will no doubt receive a gynecologic diagnosis of adhesions, pelvic inflammatory disease (PID), or endometriosis. Unexplained bowel disturbances will be given a diagnosis of IBS from a gastroenterologist, and mysterious voiding issues will be given a diagnosis of IC by a urologist. A neurologist may well view the problem as one of pudendal neuralgia. Once locked into a diagnostic paradigm, the patient will be treated accordingly and usually in terms of end-organ rather than systematic pathology.

\section{TREATING THE CAPPS PATIENT}

Given the multifaceted nature of CAPPS, it seems appropriate that the patient be approached by an integrated multidisciplinary team including representatives from surgery, pharmacy, nursing, pain medicine, nutrition, psychology, physiotherapy, neurology, gastroenterology, gynecology, urogynecology, urology, psychiatry, and social work. Such a "biopsychosocial" approach ${ }^{79}$ has been introduced, advocated, and to some degree validated in a number of areas of pain medicine, including pelvic pain. ${ }^{80-86}$

In adopting a multidisciplinary approach, it is essential to avoid the constraints imposed by the paradigms of any one element of the multifaceted condition (e.g., pain, adhesions). Accordingly, the term CAPPS is preferred over $A R D$ as well as other superficially similar terms such as "chronic visceral pain syndrome." 80 Perhaps this is what was meant by the recently expressed view that the "multidisciplinary approach dealing with the pain is far more important than finding an organic cause and cure for the pain. ${ }^{181}$ Although for the treatment of a 
patient who has entered the world of CAPPS, it may matter little that they entered through the door of IC, IBS, endometriosis, or ARD, a new opportunity exists to learn from CAPPS patients by:

1. Adapting therapies used in one variant of CAPPS in patients with a different variant. For example, sacral nerve stimulation has been shown to be effective in treating IC and is also useful in treating other CAPPS components such as chronic pelvic pain. ${ }^{87,88}$

2. Learning how to prevent patients suffering from the "monolithic" varieties of individual diseases from progressing to the multifactorial condition.

\section{IDENTIFYING RISK FACTORS FOR PROGRESSION TO CAPPS FROM THE PERSPECTIVE OF ARD}

\section{Genetic Factors}

There has long been speculation about genetic factors in ARD. The relative inability to lyse fibrin may predispose a patient to adhesions. Hypofibrinolysis, associated with an allele of the plasminogen activator inhibitor-1 (PAI1) gene, was found more often in women with endometriosis than in controls. ${ }^{89}$ More directly related to adhesions, carriers of the IL-1RN*2 allele are at greater risk for adhesion formation. ${ }^{90}$

\section{Multiple Surgeries}

A primary occurrence of adhesive small bowel obstruction (ASBO) is itself a risk factor for future obstruction. The rate of recurrence after a first ASBO was calculated $^{91}$ as $16 \%$ after 41 months (range, 1 to 75 months), $18 \%$ at 10 years, and $29 \%$ at 30 years. ${ }^{92}$ The risk of recurrent $\mathrm{ASBO}$ increased with increasing number of prior SBO episodes and reached $81 \%$ for patients with 4 or more admissions due to ASBO. Age $<40$ years, type of adhesion, and presence of postoperative complications were also identified as risk factors for ASBO. ${ }^{91}$ The effect of multiple surgeries has been noted in other CAPPS-related areas. Women with IC had significantly more pelvic surgeries than did controls, often performed before IC was diagnosed and possibly for pain related to undiagnosed IC. ${ }^{93}$ One overlooked consequence of multiple surgery is the accumulation of scar tissue within peritoneal tissue (as opposed to between peritoneal tissue, i.e., adhesions) and the effect this may have in entrapping sensory nerves, giving rise to pain and related sequelae. Perhaps one effect of repeated surgeries is to increase the population of fibroblasts of the "adhesion phenotype," ${ }^{44}$ making the recurrence of adhesions ever more likely.

\section{Hysterectomy}

Hysterectomy is associated with several CAPPS-related conditions. ${ }^{95}$ Women with IC $(N=215)$ had a higher (42\%) prevalence of hysterectomies than did controls (21\%). ${ }^{93}$ A diagnosis of IC was made 1 to 5 years after hysterectomy in most of the $68 \%$ of the possible cases. ${ }^{93}$ Hysterectomy is also associated with a high rate of SBO. ${ }^{96}$ Sixty-seven percent of patients admitted for SBO had had a hysterectomy. ${ }^{97}$ The rate of adhesionrelated obstruction after gynecologic surgery for benign conditions without hysterectomy has been estimated at $\sim 0.3 \%$. With hysterectomy, this rate may be 2 to $3 \%$ and with radical hysterectomy as high as $5 \% .{ }^{98}$

Some $56 \%$ of our own sample of 687 U.S. women had had hysterectomies (Table 2), much higher ${ }^{93,99}$ $(p<0.01)$ than the reported frequencies of 21 to

Table 4 Fraction of Patients Reporting Various Conditions with or without Hysterectomy or Hemochromatosis/IronOverload Disorder

\begin{tabular}{|c|c|c|c|c|c|c|}
\hline & + Hyst & - Hyst & + Hyst/-Hyst & $+\mathbf{H}-\mathbf{I}$ & $-\mathbf{H}-\mathbf{I}$ & $+\mathrm{H}-\mathrm{I} /-\mathrm{H}-\mathrm{I}$ \\
\hline$N$ & 387 & 300 & & 47 & 640 & \\
\hline \multicolumn{7}{|l|}{ Condition } \\
\hline + Adhesions: abdominal or pelvic & 0.97 & 0.69 & 1.40 & 1.00 & 0.84 & 1.20 \\
\hline+ Chronic pelvic or abdominal pain & 0.84 & 0.48 & 1.76 & 0.98 & 0.66 & 1.47 \\
\hline+ Endometriosis & 0.53 & 0.21 & 2.55 & 0.85 & 0.36 & 2.37 \\
\hline+ Interstitial cystitis & 0.41 & 0.12 & 3.35 & 0.83 & 0.25 & 3.36 \\
\hline+ IBS & 0.71 & 0.34 & 2.08 & 0.98 & 0.52 & 1.90 \\
\hline + Recurrent obstruction & 0.55 & 0.29 & 1.86 & 0.89 & 0.40 & 2.23 \\
\hline + Fibroids & 0.38 & 0.12 & 3.28 & 0.87 & 0.22 & 3.93 \\
\hline$+\mathrm{PID}$ & 0.22 & 0.04 & 5.07 & 0.81 & 0.09 & 8.62 \\
\hline + Hemochromatosis/ iron-overload disorder & 0.11 & 0.013 & 8.33 & & & \\
\hline Hysterectomy & & & & 0.91 & 0.54 & 1.70 \\
\hline Geometric mean of fractions/ratios & 0.44 & 0.16 & 2.82 & 0.90 & 0.36 & 2.47 \\
\hline
\end{tabular}

Hyst, hysterectomy; $\mathrm{H}-\mathrm{I}$, hemochromatosis or iron-overload disorder. 
$33 \%{ }^{100}$ in control populations. The rates of the various CAPPS-related conditions in this population was higher $(p<0.001)$ for each of the conditions in patients with a hysterectomy than in those without (Table 4).

Whether this effect of hysterectomy is reflective of collaterally damaged pelvic structures or a common pathology predisposing a patient to CAPPS is unclear. Alternatively, hysterectomy may place a woman at risk for oxidative stress related to iron overload as iron is no longer eliminated through menstruation. ${ }^{101,102}$ The protective estrogenic effect against oxidative stress may also have been a factor. ${ }^{103,104}$ Oxidative stress and its amelioration has been discussed in the context of adhesions ${ }^{105,106}$ or endometriosis ${ }^{107}$ but not in regard to hysterectomy and adhesions.

\section{Susceptibility to Oxidative Stress: Hemochromatosis and Iron-Overload Disorder}

The frequency of a diagnosis of hemochromatosis or iron-overload disorder in patients with a hysterectomy was more than 8 times that in patients without (Table 4). The most common form in the United States is hereditary hemochromatosis (HHC), a recessive disorder resulting mainly from one of several $\mathrm{HFE}$ gene mutations. HHC affects $\sim 0.5 \%$ of the population $^{108}$ and is characterized by iron deposition in multiple organs, liver disease, heart disease, joint disease, diabetes, and early death. Its symptoms include fatigue and joint and abdominal pain. ${ }^{109} \mathrm{HHC}$ may be a cause of infertility. ${ }^{110}$ Accumulated iron participates in redox reactions and the generation of reactive oxygen species leading to tissue damage via the peroxidation of lipids, proteins, and nucleic acid. ${ }^{111,112} \mathrm{~A}$ role for iron has been suggested in the pathogenesis of endometriosis. $^{113-115}$

Of our sample of U.S. CAPPS-ARD patients, $6.8 \%$ (47 of 687 ) reported a diagnosis of hemochromatosis (HC) $(5.1 \%)$ or iron-overload disorder (IOD) (5.7\%) with substantial overlap. The frequency of $\mathrm{HC}$ patients is well above that expected $(0.5 \%)$ in the general population $(p<0.001)$. The rates of various CAPPSrelated conditions in this population was higher $(p<0.001)$ for each of the conditions in patients with $\mathrm{HC} / \mathrm{IOD}$ than in those without (Table 4).

HHC heterozygotes, though not displaying a history of HHC, carry risks of iron overload ${ }^{116-119}$ and an altered pattern of fibrosis or inflammation. ${ }^{120,121}$ Because inflammation alters iron homeostasis, ${ }^{122,123}$ HHC heterozygotes ( $25 \%$ in the United States) undergoing surgery may be at increased risk of adhesions or other complications and may suffer from more severe forms of other CAPPS-related conditions and may be less responsive to prophylaxis or treatment.

Support for this hypothesis comes from our preliminary work concerning possible Intergel Reac- tion Syndrome (pIRS). ${ }^{124}$ Intergel (ferric hyaluronate [FeHA]) was a gel of ferric hyaluronate used for adhesion prevention but withdrawn due to reports of lateonset pain, unexplained fever, infection, peritoneal reactions, and several deaths. ${ }^{8,125}$ Based on the possibility that the difference between the production of a granulomatous peritonitis in immature and mature rats in response to Intergel ${ }^{126}$ could be accounted for by developmental differences in the expression of hepcidin, a regulator of iron transport, ${ }^{127}$ we hypothesized that a similar subclinical deficiency in iron regulation, such as HHC heterozygosity, may contribute to pIRS. Compared with $\sim 25 \%$ of the population, 3 of 7 (43\%) patients reporting a reaction to Intergel had one of the three HFE main mutations. These patients, along with two others, were of Irish/Scottish ancestry, known to have a high prevalence of HHC. Three of the HFEnormozygotes and one of the HFE heterozygotes had had a prior hysterectomy, a finding that approached $(p=0.08)$ or exceeded $(p=0.03)$ significance depending whether a figure of $33 \%{ }^{100}$ or $21 \%{ }^{93,99}$ is taken as the control prevalence of hysterectomy. Thus, the combination of surgery (disturbing iron homeostasis), the propensity to iron overload (either because of a HFE mutation or prior hysterectomy), and the administration of a bolus dose of iron into a single physiologic compartment (as Intergel, delivered intraperitoneally) may have led to the development of pIRS.

This finding has implications beyond pIRS. Because the differences in population frequencies of $\mathrm{HFE}$ mutations may account for intercontinental differences in adverse event rates to Intergel, ${ }^{128}$ those same differences may influence the relative propensity of populations to form adhesions, to respond to antiadhesion measures, to succumb to other conditions, and for those conditions to progress to a multifaceted condition such as CAPPS. Other examples of genes that regulate oxidation for which this argument could be advanced include those for catechol-O-methyltransferase (COMT) ${ }^{129}$ and GTP cyclohydrolase $(\mathrm{GCH} 1){ }^{130}$ polymorphisms that influence sensitivity to pain. Lastly, these findings have implications for the use of antioxidants and modulators of iron metabolism in the prophylaxis and treatment of CAPPS-related conditions.

\section{CONCLUSIONS}

Although great strides have been made in understanding adhesions, preventing them, and curbing adhesion-related sequelae, "adhesions" can no longer be considered a monolithic entity. Although "adhesions" may start out as a monolithic entity, a patient with "adhesions" may develop related conditions (ARD) until they are practically indistinguishable from patients with multiple symptoms stemming from other pelvic or abdominal pathologies to the point that they coalesce into a new 
pathologic entity. Rather than use terms that constrain the approach to these patients by the paradigms of the specialty related to the patient's initial symptom set, it is proposed that a term such as complex abdominopelvic and pain syndrome (CAPPS) be used to allow the unencumbered development of a multidisciplinary biopsychosocial approach.

It is essential to understand not only the pathogenesis of the "initiating" conditions but also how they progress to CAPPS. In the case of adhesions, we have some understanding of how adhesions form and the breadth of problems experienced by the severe adhesions patient. But we have little understanding of how adhesions become ARD and how ARD becomes CAPPS. On the positive side, we can begin to apply what we have learned about the treatment of CAPPS stemming from other pathologies to the treatment of CAPPS stemming from adhesions.

\section{ACKNOWLEDGMENTS}

The author gratefully acknowledges the many thousands of patients whose personal communications have given a face to the suffering of adhesions and a sense of urgency in our quest to solve the problem. The author also thanks the numerous medical and patient volunteers around the world who have provided help and assistance to the adhesions.org Web site, especially Roberta and Bruce Speyer of OBGYN.net for making the work of adhesions.org possible.

\section{ABBREVIATIONS}

$\begin{array}{ll}\text { AFS } & \text { American Fertility Society } \\ \text { ARD } & \text { adhesion- related disorder } \\ \text { ASBO } & \text { adhesive small bowel obstruction } \\ \text { CAPPS } & \text { complex abdominopelvic and pain syndrome } \\ \text { COMT } & \begin{array}{l}\text { catechol-O-methyltransferase } \\ \text { chronic pelvic pain }\end{array} \\ \text { CPP } & \text { GTP cyclohydrolase } \\ \text { GCH1 } & \text { hemochromatosis } \\ \text { HC } & \text { hereditary hemochromatosis } \\ \text { HHC } & \text { irritable bowel syndrome } \\ \text { IBS } & \text { interstitial cystitis } \\ \text { IC } & \text { iron-overload disorder } \\ \text { IOD } & \text { plasminogen activator inhibitor-1 } \\ \text { PAI-1 } & \text { pelvic inflammatory disease } \\ \text { PID } & \text { possible Intergel reaction syndrome } \\ \text { pIRS } & \text { small bowel obstruction }\end{array}$

\section{REFERENCES}

1. Wiseman DM. Adhesion prevention: past the future. In: diZerega G, DeCherney A, Diamond M, et al, eds. Peritoneal Surgery. New York, NY: Springer-Verlag; 2000: 401-418
2. Wiseman DM, Trout JR, Franklin RR, Diamond MP. Metaanalysis of the safety and efficacy of an adhesion barrier (Interceed TC7) in laparotomy. J Reprod Med 1999;44: 325-331

3. Beck DE, Cohen Z, Fleshman JW, Kaufman HS, van Goor $\mathrm{H}$, Wolff BG. A prospective, randomized, multicenter, controlled study of the safety of Seprafilm adhesion barrier in abdominopelvic surgery of the intestine. Dis Colon Rectum 2003;46:1310-1319

4. Diamond MP. Reduction of adhesions after uterine myomectomy by Seprafilm membrane (HAL-F): a blinded, prospective, randomized, multicenter clinical study. Seprafilm Adhesion Study Group. Fertil Steril 1996;66:904-910

5. Haney AF, Hesla J, Hurst BS, et al. Expanded polytetrafluoroethylene (Gore-Tex Surgical Membrane) is superior to oxidized regenerated cellulose (Interceed TC7) in preventing adhesions. Fertil Steril 1995;63:1021-1026

6. Diamond MP and the Sepracoat Adhesion Study Group. Reduction of de novo postsurgical adhesions by intraoperative precoating with Sepracoat (HAL-C) solution: a prospective, randomized, blinded, placebo-controlled multicenter study. The Sepracoat Adhesion Study Group. Fertil Steril 1998;69:1067-1074

7. Johns DB, Keyport GM, Hoehler F, diZerega GS. Reduction of postsurgical adhesions with Intergel adhesion prevention solution: a multicenter study of safety and efficacy after conservative gynecologic surgery. Fertil Steril 2001;76:595-604

8. Wiseman DM. Possible Intergel reaction syndrome (pIRS). Ann Surg 2006;244:630-632

9. Holmdahl L. Mechanisms of adhesion development and effects on wound healing. Eur J Surg Suppl 1997;579:7-9

10. Practice Committee of the American Society for Reproductive Medicine. Pathogenesis, consequences, and control of peritoneal adhesions in gynecologic surgery. Fertil Steril 2007;88:21-26

11. Liakakos T, Thomakos N, Fine PM, Dervenis C, Young RL. Peritoneal adhesions: etiology, pathophysiology, and clinical significance. Recent advances in prevention and management. Dig Surg 2001;18:260-273

12. Lower AM, Hawthorn RJ, Clark D, et al. Adhesion-related readmissions following gynaecological laparoscopy or laparotomy in Scotland: an epidemiological study of 24046 patients. Hum Reprod 2004;19:1877-1885

13. Lower AM, Hawthorn RJ, Ellis H, O'Brien F, Buchan S, Crowe AM. The impact of adhesions on hospital readmissions over ten years after 8849 open gynaecological operations: an assessment from the Surgical and Clinical Adhesions Research Study. BJOG 2000;107:855-862

14. Ivarsson ML, Holmdahl L, Franzen G, Risberg B. Cost of bowel obstruction resulting from adhesions. Eur J Surg 1997; 163:679-684

15. Jeekel H. Cost implications of adhesions as highlighted in a European study. Eur J Surg Suppl 1997;579:43-45

16. Ray NF, Denton WG, Thamer M, Henderson SC, Perry S. Abdominal adhesiolysis: inpatient care and expenditures in the United States in 1994. J Am Coll Surg 1998;186:1-9

17. Farquhar C, Vandekerckhove P, Watson A, Vail A, Wiseman D. Barrier agents for preventing adhesions after surgery for subfertility. Cochrane Database Syst Rev 2000: CD000475

18. Wiseman DM. Correlations between animal and human models of adhesions. Diamond MP, DeCherney AH, eds. 
Infertility and Reproductive, Medical Clinics of North America; 2003:391-401

19. Attard JA, MacLean AR. Adhesive small bowel obstruction: epidemiology, biology and prevention. Can J Surg 2007;50: 291-300

20. Al-Jaroudi D, Tulandi T. Adhesion prevention in gynecologic surgery. Obstet Gynecol Surv 2004;59:360-367

21. Diamond MP, Freeman ML. Clinical implications of postsurgical adhesions. Hum Reprod Update 2001;7:567576

22. Food and Drug Administration. Guidance for resorbable adhesion barrier devices for use in abdominal and/or pelvic surgery; Guidance for Industry. 2002. Available at: www.fda.gov/cdrh/ode/guidance/1356.pdf. Accessed November 23, 2006

23. Ellis H, Moran BJ, Thompson JN, et al. Adhesion-related hospital readmissions after abdominal and pelvic surgery: a retrospective cohort study. Lancet 1999;353:1476-1480

24. Fushiki H, Ikoma T, Kobayashi H, Yoshimoto H. Efficacy of Seprafilm as an adhesion barrier in cesarean sections. Obstet Gynecol Treatment 2005;91:557-561

25. Inoue M, Uchida K, Miki C, Kusunoki M. Efficacy of Seprafilm for reducing reoperative risk in pediatric surgical patients undergoing abdominal surgery. J Pediatr Surg 2005;40:1301-1306

26. Salum M, Wexner SD, Nogueras JJ, et al. Does sodium hyaluronate- and carboxymethylcellulose-based bioresorbable membrane (Seprafilm) decrease operative time for loop ileostomy closure? Tech Coloproctol 2006;10:187-190

27. American Fertility Society. The American Fertility Society classifications of adnexal adhesions, distal tubal occlusion, tubal occlusion secondary to tubal ligation, tubal pregnancies, mullerian anomalies and intrauterine adhesions. Fertil Steril 1988;49:944-955

28. Bronson RA, Wallach EE. Lysis of periadnexal adhesions for correction of infertility. Fertil Steril 1977;28:613-619

29. Marana R, Rizzi M, Muzii L, Catalano GF, Caruana P, Mancuso S. Correlation between the American Fertility Society classifications of adnexal adhesions and distal tubal occlusion, salpingoscopy, and reproductive outcome in tubal surgery. Fertil Steril 1995;64:924-929

30. Marana R, Catalano GF, Muzii L, Caruana P, Margutti F, Mancuso S. The prognostic role of salpingoscopy in laparoscopic tubal surgery. Hum Reprod 1999;14:29912995

31. Tulandi T, Collins JA, Burrows E, et al. Treatmentdependent and treatment-independent pregnancy among women with periadnexal adhesions. Am J Obstet Gynecol 1990;162:354-357

32. Sawada T, Nishizawa H, Nishio E, Kadowaki M. Postoperative adhesion prevention with an oxidized regenerated cellulose adhesion barrier in infertile women. J Reprod Med 2000;45:387-389

33. Ellis H. The clinical significance of adhesions: focus on intestinal obstruction. Eur J Surg Suppl 1997;579:5-9

34. Wilson MS, Ellis H, Menzies D, Moran BJ, Parker MC, Thompson JN. A review of the management of small bowel obstruction. Members of the Surgical and Clinical Adhesions Research Study (SCAR). Ann R Coll Surg Engl 1999;81:320-328

35. Nagle A, Ujiki M, Denham W, Murayama K. Laparoscopic adhesiolysis for small bowel obstruction. Am J Surg 2004; 187:464-470
36. Fazio VW, Cohen Z, Fleshman JW, et al. Reduction in adhesive small-bowel obstruction by Seprafilm adhesion barrier after intestinal resection. Dis Colon Rectum 2006; 49:1-11

37. Mohri Y, Uchida K, Araki T, et al. Hyaluronic acidcarboxycellulose membrane (Seprafilm) reduces early postoperative small bowel obstruction in gastrointestinal surgery. Am Surg 2005;71:861-863

38. Kudo FA, Nishibe T, Miyazaki K, Murashita T, Nishibe M, Yasuda K. Use of bioresorbable membrane to prevent postoperative small bowel obstruction in transabdominal aortic aneurysm surgery. Surg Today 2004;34:648-651

39. Zeng Q, Yu Z, You J, Zhang Q. Efficacy and safety of Seprafilm for preventing postoperative abdominal adhesion: systematic review and meta-analysis. World J Surg 2007; 31:2125-2131

40. Alexander-Williams J. Do adhesions cause pain? Br Med J (Clin Res Ed) 1987;294:659-660

41. Hammoud A, Gago LA, Diamond MP. Adhesions in patients with chronic pelvic pain: a role for adhesiolysis? Fertil Steril 2004;82:1483-1491

42. Herrick SE, Mutsaers SE, Ozua P, et al. Human peritoneal adhesions are highly cellular, innervated, and vascularized. J Pathol 2000;192:67-72

43. Demco L. Pain mapping of adhesions. J Am Assoc Gynecol Laparosc 2004;11:181-183

44. Howard FM. The role of laparoscopy in chronic pelvic pain: promise and pitfalls. Obstet Gynecol Surv 1993;48:357-387

45. Freys SM, Fuchs KH, Heimbucher J, Thiede A. Laparoscopic adhesiolysis. Surg Endosc 1994;8:1202-1207

46. Steege JF, Stout AL. Resolution of chronic pelvic pain after laparoscopic lysis of adhesions. Am J Obstet Gynecol 1991; 165:278-281

47. Daniell JF. Laparoscopic enterolysis for chronic abdominal pain. J Gynecol Surg 1989;5:61-66

48. Peters AA, Trimbos-Kemper GC, Admiraal C, Trimbos JB, Hermans J. A randomized clinical trial on the benefit of adhesiolysis in patients with intraperitoneal adhesions and chronic pelvic pain. Br J Obstet Gynaecol 1992;99:59-62

49. Baker PN, Symonds EM. The resolution of chronic pelvic pain after normal laparoscopy findings. Am J Obstet Gynecol 1992;166:835-836

50. Swank DJ, Swank-Bordewijk SC, Hop WC, et al. Laparoscopic adhesiolysis in patients with chronic abdominal pain: a blinded randomised controlled multi-centre trial. Lancet 2003;361:1247-1251

51. Moseley JB, O’Malley K, Petersen NJ, et al. A controlled trial of arthroscopic surgery for osteoarthritis of the knee. N Engl J Med 2002;347:81-88

52. Jarrell J, Mohindra R, Ross S, Taenzer P, Brant R. Laparoscopy and reported pain among patients with endometriosis. J Obstet Gynaecol Can 2005;27:477-485

53. Wiseman DM; Trout JR, Diamond MP. The rates of adhesion development and the effects of crystalloid solutions on adhesion development in pelvic surgery. Fertil Steril 1998;70(4):702-711

54. Khaitan L, Scholz S, Houston HL, Richards WO. Results after laparoscopic lysis of adhesions and placement of Seprafilm for intractable abdominal pain. Surg Endosc 2003;17:247-253

55. Menzies D, Ellis H. Intestinal obstruction from adhesionshow big is the problem? Ann R Coll Surg Engl 1990;72:6063 
56. Wiseman DM. Polymers for the prevention of surgical adhesions. In: Domb AJ, ed. Polymeric Site-Specific Pharmacotherapy. Chichester, England: John Wiley; 1994: 369-421

57. Wiseman D. Information and consent regarding adhesions: an internet survey. J Minim Invasive Gynecol 2006;13:S73

58. Ellis $\mathrm{H}$. Medicolegal consequences of adhesions. Hosp Med 2004;65:348-350

59. Courtney MJ. Information about surgery: what does the public want to know? Aust N Z J Surg 2001;71:24-26

60. Lloyd A, Hayes P, Bell PR, Naylor AR. The role of risk and benefit perception in informed consent for surgery. Med Decis Making 2001;21:141-149

61. Wiseman D. Severe adhesion related disorder (ARD); pattern of bowel dysfunction and obstruction, social and physician issues: an Internet survey. J Minim Invasive Gynecol 2006;13:S65-S66

62. Kotarinos RK. Pelvic floor physical therapy in urogynecologic disorders. Curr Womens Health Rep 2003;3:334-339

63. Vizzard MA. Alterations in spinal cord Fos protein expression induced by bladder stimulation following cystitis. Am J Physiol Regul Integr Comp Physiol 2000;278:R1027R1039

64. LaBerge J, Malley SE, Zvarova K, Vizzard MA. Expression of corticotropin-releasing factor and CRF receptors in micturition pathways after cyclophosphamide-induced cystitis. Am J Physiol Regul Integr Comp Physiol 2006;291: R692-R703

65. Qiao LY, Vizzard MA. Cystitis-induced upregulation of tyrosine kinase (TrkA, $\operatorname{TrkB})$ receptor expression and phosphorylation in rat micturition pathways. J Comp Neurol 2002;454:200-211

66. Melzack R. Phantom limb pain. Patol Fiziol Eksp Ter 1992;4:52-54

67. Brena SF, Sammons EE. Phantom urinary bladder paincase report. Pain 1979;7:197-201

68. Biley FC. Phantom bladder sensations: a new concern for stoma care workers. Br J Nurs 2001;10:1290-1296

69. Rogers RM. Basic pelvic neuroanatomy. In: Steege JF, Metzger DA, Levy BS, eds. Chronic Pelvic Pain. Philadelphia, PA: W.B. Saunders; 1998:31-58

70. Wesselmann U, Burnett AL, Heinberg LJ. The urogenital and rectal pain syndromes. Pain 1997;73:269-294

71. Pezzone MA, Liang R, Fraser MO. A model of neural cross-talk and irritation in the pelvis: implications for the overlap of chronic pelvic pain disorders. Gastroenterology 2005;128:1953-1964

72. Giamberardino MA, Berkley KJ, Affaitati G, et al. Influence of endometriosis on pain behaviors and muscle hyperalgesia induced by a ureteral calculosis in female rats. Pain 2002;95:247-257

73. Bielefeldt K, Lamb K, Gebhart GF. Convergence of sensory pathways in the development of somatic and visceral hypersensitivity. Am J Physiol Gastrointest Liver Physiol 2006;291:G658-G665

74. Ustinova EE, Fraser MO, Pezzone MA. Colonic irritation in the rat sensitizes urinary bladder afferents to mechanical and chemical stimuli: an afferent origin of pelvic organ cross-sensitization. Am J Physiol Renal Physiol 2006;290: F1478-F1487

75. Winnard KP, Dmitrieva N, Berkley KJ. Cross-organ interactions between reproductive, gastrointestinal, and urinary tracts: modulation by estrous stage and involvement of the hypogastric nerve. Am J Physiol Regul Integr Comp Physiol 2006;291:R1592-R1601

76. Gomel V. Chronic pelvic pain: a challenge. J Minim Invasive Gynecol 2007;14:521-526

77. Zondervan KT, Yudkin PL, Vessey MP, et al. Chronic pelvic pain in the community-symptoms, investigations, and diagnoses. Am J Obstet Gynecol 2001;184:1149-1155

78. Stanford EJ, Koziol J, Feng A. The prevalence of interstitial cystitis, endometriosis, adhesions, and vulvar pain in women with chronic pelvic pain. J Minim Invasive Gynecol 2005; 12:43-49

79. Engel GL. The need for a new medical model: a challenge for biomedicine. Science 1977;196:129-136

80. Wesselmann U, Czakanski PP. Pelvic pain: a chronic visceral pain syndrome. Curr Pain Headache Rep 2001;5:13-19

81. Peters AA, Van den Tillaart SA. The difficult patient in gastroenterology: chronic pelvic pain, adhesions, and sub occlusive episodes. Best Pract Res Clin Gastroenterol 2007; 21:445-463

82. Stanford EJ, Dell JR, Parsons CL. The emerging presence of interstitial cystitis in gynecologic patients with chronic pelvic pain. Urology 2007;69:53-59

83. Levey KA. Chronic pelvic pain. J Minim Invasive Gynecol 2004;11:546

84. Peters AA, van Dorst E, Jellis B, van Zuuren E, Hermans J, Trimbos JB. A randomized clinical trial to compare two different approaches in women with chronic pelvic pain. Obstet Gynecol 1991;77:740-744

85. Reiter RC. Evidence-based management of chronic pelvic pain. Clin Obstet Gynecol 1998;41:422-435

86. Steege JF, Stout AL, Somkuti SG. Chronic pelvic pain in women: toward an integrative model. Obstet Gynecol Surv 1993;48:95-110

87. Peters KM. Neuromodulation for the treatment of refractory interstitial cystitis. Rev Urol 2002;4(Suppl 1):S36-S43

88. Kapural L, Narouze SN, Janicki TI, Mekhail N. Spinal cord stimulation is an effective treatment for the chronic intractable visceral pelvic pain. Pain Med 2006;7:440-443

89. Bedaiwy MA, Falcone T, Mascha EJ, Casper RF. Genetic polymorphism in the fibrinolytic system and endometriosis. Obstet Gynecol 2006;108:162-168

90. Wieser F, Tempfer C, Schneeberger C, van Trotsenburg M, Huber J, Wenzl R. Interleukin-1 receptor antagonist polymorphism in women with peritoneal adhesions. BJOG 2002;109:1298-1300

91. Duron JJ, Silva NJ, du Montcel ST, et al. Adhesive postoperative small bowel obstruction: incidence and risk factors of recurrence after surgical treatment: a multicenter prospective study. Ann Surg 2006;244:750-757

92. Fevang BT, Fevang J, Lie SA, Soreide O, Svanes K, Viste A. Long-term prognosis after operation for adhesive small bowel obstruction. Ann Surg 2004;240:193-201

93. Ingber MS, Peters KM, Killinger KA, Carrico DJ, Ibrahim IA, Diokno AC. Dilemmas in diagnosing pelvic pain: multiple pelvic surgeries common in women with interstitial cystitis. Int Urogynecol J Pelvic Floor Dysfunct 2008;19: 341-345

94. Saed GM, Diamond MP. Molecular characterization of postoperative adhesions: the adhesion phenotype. J Am Assoc Gynecol Laparosc 2004;11:307-314

95. Kluivers KB, Mol BW, Bremer GL, Brolmann HA, Vierhout ME, Bongers MY. Pelvic organ function in 
randomized patients undergoing laparoscopic or abdominal hysterectomy. J Minim Invasive Gynecol 2007;14: 442-448

96. Stricker B, Blanco J, Fox HE. The gynecologic contribution to intestinal obstruction in females. J Am Coll Surg 1994; 178:617-620

97. Ratcliff JB, Kapernick P, Brooks GG, Dunnihoo DR. Small bowel obstruction and previous gynecologic surgery. South Med J 1983;76:1349-1350

98. Monk BJ, Berman ML, Montz FJ. Adhesions after extensive gynecologic surgery: clinical significance, etiology, and prevention. Am J Obstet Gynecol 1994;170:1396-1403

99. Brett KM, Higgins JA. Hysterectomy prevalence by Hispanic ethnicity: evidence from a national survey. Am J Public Health 2003;93:307-312

100. Centers for Disease Control and Prevention. Hysterectomy prevalence and death rates for cervical cancer-United States, 1965-1988. MMWR Morb Mortal Wkly Rep 1992;41:1720

101. Moirand R, Adams PC, Bicheler V, Brissot P, Deugnier $\mathrm{Y}$. Clinical features of genetic hemochromatosis in women compared with men. Ann Intern Med 1997;127: 105-110

102. Cade JE, Moreton JA, O'Hara B, et al. Diet and genetic factors associated with iron status in middle-aged women. Am J Clin Nutr 2005;82:813-820

103. Bureau I, Gueux E, Mazur A, Rock E, Roussel AM, Rayssiguier Y. Female rats are protected against oxidative stress during copper deficiency. J Am Coll Nutr 2003;22: 239-246

104. Persky AM, Green PS, Stubley L, et al. Protective effect of estrogens against oxidative damage to heart and skeletal muscle in vivo and in vitro. Proc Soc Exp Biol Med 2000; 223:59-66

105. Binda MM, Molinas CR, Koninckx PR. Reactive oxygen species and adhesion formation: clinical implications in adhesion prevention. Hum Reprod 2003;18:2503-2507

106. Alpay Z, Saed GM, Diamond MP. Female infertility and free radicals: potential role in adhesions and endometriosis. J Soc Gynecol Investig 2006;13:390-398

107. Gupta S, Agarwal A, Krajcir N, Alvarez JG. Role of oxidative stress in endometriosis. Reprod Biomed Online 2006;13:126-134

108. McDonnell SM, Preston BL, Jewell SA, et al. A survey of 2,851 patients with hemochromatosis: symptoms and response to treatment. Am J Med 1999;106:619-624

109. Burke W, Reyes M, Imperatore G. Hereditary haemochromatosis: a realistic approach to prevention of iron overload disease in the population. Best Pract Res Clin Haematol 2002;15:315-328

110. Tweed MJ, Roland JM. Haemochromatosis as an endocrine cause of subfertility. BMJ 1998;316:915-916

111. Britton RS, Ramm GA, Olynyk J, Singh R, O'Neill R, Bacon BR. Pathophysiology of iron toxicity. Adv Exp Med Biol 1994;356:239-253

112. Goswami T, Rolfs A, Hediger MA. Iron transport: emerging roles in health and disease. Biochem Cell Biol 2002;80:679-689
113. Arumugam K, Yip YC. De novo formation of adhesions in endometriosis: the role of iron and free radical reactions. Fertil Steril 1995;64:62-64

114. Van Langendonckt A, Casanas-Roux F, Donnez J. Iron overload in the peritoneal cavity of women with pelvic endometriosis. Fertil Steril 2002;78:712-718

115. Defrere S, Van Langendonckt A, Vaesen S, et al. Iron overload enhances epithelial cell proliferation in endometriotic lesions induced in a murine model. Hum Reprod 2006; 21:2810-2816

116. Sullivan JL. Iron and the genetics of cardiovascular disease. Circulation 1999;100:1260-1263

117. Weinberg ED. Do some carriers of hemochromatosis gene mutations have higher than normal rates of disease and death? Biometals 2002;15:347-350

118. Holmstrom P, Marmur J, Eggertsen G, Gafvels M, Stal P. Mild iron overload in patients carrying the HFE S65C gene mutation: a retrospective study in patients with suspected iron overload and healthy controls. Gut 2002;51:723-730

119. Adams PC. Hemochromatosis. Clin Liver Dis 2004;8:735753 vii

120. Eisenbach C, Gehrke SG, Stremmel W. Iron, the HFE gene, and hepatitis C. Clin Liver Dis 2004;8:775-785viiviii

121. Geier A, Reugels M, Weiskirchen R, et al. Common heterozygous hemochromatosis gene mutations are risk factors for inflammation and fibrosis in chronic hepatitis C. Liver Int 2004;24:285-294

122. Andrews NC. Anemia of inflammation: the cytokinehepcidin link. J Clin Invest 2004;113:1251-1253

123. Weiss G. Iron and anemia of chronic disease. Kidney Int Suppl 1999;69:S12-S17

124. Wiseman D. Possible Intergel reaction syndrome (pIRS): mechanisms and general consequences for patients undergoing surgery. J Minim Invasive Gynecol 2006;13:S67

125. Wiseman DM. Registries for anti-adhesion products? Fertil Steril 2006;86:771

126. Lifecore Biomedical, Inc. Major Amendment to INTERGEL PMA P99015/A010 Appendix C: Summary of Safety and Effectiveness (Revised). June 2, 2000Available at: www.fda.gov/ohrms/dockets/ac/01/briefing/3789b1_12_08_ summary\%20of\%20S\&E.pdf. Accessed March 24, 2005

127. Courselaud B, Pigeon C, Inoue $\mathrm{Y}$, et al. C/EBPalpha regulates hepatic transcription of hepcidin, an antimicrobial peptide and regulator of iron metabolism. Cross-talk between C/EBP pathway and iron metabolism. J Biol Chem 2002;277:41163-41170

128. Horbowyj R. INTERGEL Adhesion Prevention Solution. Clinical study of use during laparotomy for gynecologic interventions - FDA Clinical Perspective. September 6, 2001. Available at: www.fda.gov/ohrms/dockets/ac/01/ briefing/3789b1_08.ppt. Accessed March 28, 2005

129. Diatchenko L, Nackley AG, Slade GD, et al. Catechol-Omethyltransferase gene polymorphisms are associated with multiple pain-evoking stimuli. Pain 2006;125:216-224

130. Tegeder I, Costigan M, Griffin RS, et al. GTP cyclohydrolase and tetrahydrobiopterin regulate pain sensitivity and persistence. Nat Med 2006;12:1269-1277 